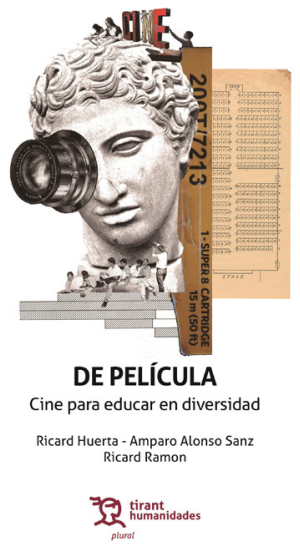

De película. Cine para educar en diversidad

Ricard Huerta, Amparo Alonso Sanz y Ricard

Ramon

Año. 2019 Lugar. València,

Editorial: Tirant Humanidades

Páginas: 246

ISBN: 978-84-17706-93-7

\title{
Diversidad, cine y educación
}

Esta obra recurre al concepto "diversidad" y lo rescata como todo el conjunto de diferencias que hay entre quienes componen un grupo de personas en todos los niveles y clasificaciones (físicas, psicológicas, evolutivas, religiosas, sexuales, familiares, etc.), potenciando un empoderamiento y atribuyéndole connotaciones positivas que defienden la necesidad de esta disonancia en la cotidianidad. Concretamente, se focaliza la atención en cómo esta diversidad se evidencia cada vez con más notoriedad en las aulas - independientemente del curso/etapa donde se encuentren -, la cual a su vez debe ser respetada, visibilizada y preservada. Por ello, a lo largo de toda la obra ofrecen diferentes recursos y estrategias didácticas, pedagógicas y metodológicas para abordarla en base a valores de tolerancia y respeto, desde el cine. Estas no deben ser tomadas como un manual, sino como unas pinceladas para que cada profesional amplíe su campo de actuación y tome iniciativas en los procesos de enseñanza-aprendizaje en los que actúa como guía.

Esta obra comienza con una exposición de las diversidades más destacadas a través de ejemplos cinematográficos clave que las introducen. También se elabora un plano general a nivel educativo en el que se muestran inconvenientes para su introducción en el aula como la escasez de formación en el profesorado o el desconocimiento por este grupo de las potencialidades que tiene. En contraposición se destaca el gran beneficio que genera en una educación de calidad en valores y sobre todo a nivel integral en una realidad en la que la imagen y los medios de comunicación audiovisual son lo más destacable. Asimismo, de esta manera la autoría del libro introduce también el concepto de "estética" en el ámbito cinematográfico.

Finalmente, se destaca como particular aproximación que realizan hacia la diversidad cultural de los patrimonios que ayuda a entender la disonancia entre culturas y el enriquecimiento que suponen cuando estas se combinan y nutren las unas de las otras. Pero también cuando mencionan el cine como una herramienta de 
acercamiento al TEA. Con todo, hay un guiño a la relación entre las tipografías del cine y las historias que se narran con cada filme. Manifestando la complementariedad que adquieren las primeras a las segundas.

A modo de cierre de esta reseña, se destaca la gran asequibilidad que supone al colectivo de plantillas docentes como una lectura para tener en cuenta en su labor profesional y replantearse la posibilidad de introducir en sus programaciones el cine, considerándolo una parte imprescindible del currículo. Así, se rescata la siguiente cita literal de este escrito: "Cualquier diferencia ha de suponer una oportunidad de cambio y mejora. Por ello pensamos que todas las diversidades son, en realidad, de cine, es decir, opciones magníficas para hacer visibles las diferencias" (p. 12).

Vicente Monleón. CREARI, Grup de recerca en pedagogies culturals. 